\title{
ESTUDO DAS PATOLOGIAS NA VIA PERMANENTE DA FERROESTE ENTRE PÁTIO CASCAVEL E PÁTIO CAMPO BONITO/PR
}

\author{
M. E. Guimarães ${ }^{1}$; T. M. Basso ${ }^{2}$ \\ ${ }^{1}$ Universidade Federal da Integração Latino-Americana (UNILA), Av. Tancredo Neves, no 6713, Parque \\ Tecnológico da Itaipu (PTI), Foz do Iguaçu/PR \\ ${ }^{2}$ Centro Universitário Fundação Assis Gurgacz, Av. das torres, no 500, Loteamento FAG, Cascavel /PR \\ marciogeng@hotmail.com ${ }^{1}$, thalytabasso@hotmail.com ${ }^{2}$
}

\begin{abstract}
Resumo: O modal ferroviário está cada vez mais degradado com falta de investimentos em conservação, abrindo espaço para o aparecimento de manifestaçôes patológicas em suas vias. Em função disso, o presente trabalho teve como objetivo realizar um levantamento das manifestaçóes patológicas do trecho da via férrea do Posto Cascavel até o Posto Campo Bonito - PR, da FERROESTE e sugerir procedimentos de manutenção das mesmas. Foram diagnosticados os fenômenos patológicos apresentados, identificando o grau de comprometimento da via causado pelas patologias incidentes e também as possíveis soluçóes para o combate de tais fenômenos. Dos $25 \mathrm{~km}$ analisados, $12 \mathrm{~km}$ apresentaram patologias, destas, as mais incidentes foram o crescimento de vegetação com $15,25 \%$ de ocorrência e despedaçamento do canto de bitola com 13,56\%. O maior grau de comprometimento deu-se no km 226, no qual foi encontrada a maior quantidade de patologias. Conclui-se que é de suma importância a manutençáo preventiva na via permanente, pois além do controle do uso da via, medidas como fiscalização nos trilhos devem ocorrer com frequência, para que se observe qualquer alteração no seu estado físico, antecipando uma possível patologia que possa vir a ocorrer.
\end{abstract}

Palavras-chave: Ferrovias, Via permanente, Manifestações patológicas em estrada de ferro.

Abstract: The railway modal is increasingly degraded with a lack of investments in conservation, its can enable the appearance of pathological manifestations in its pathways. Following this situation, the present paper had as objective to perform a survey of the pathological manifestations of the section of the railroad between Cascavel Post and Campo Bonito Post - PR, of FERROESTE and to suggest procedures of maintenance of the same ones. In this way, the pathological phenomena presented were diagnosed, presenting the degree of pathway impairment caused by the incident pathologies and also the possible solutions to combat such phenomena. Of the $25 \mathrm{~km}$ analysed, 12 $\mathrm{km}$ presented pathologies, of these, the most incidents were the growth of vegetation with $15.25 \%$ of occurrence and breaking of the corner of gauge with $13.56 \%$. The greatest degree of impairment occurred at $\mathrm{km} \mathrm{226}$, in which the greatest number of pathologies were found. We conclude that preventive maintenance in the permanent route is of paramount importance, since in addition to the control of the use of the road, measures such as supervision on the rails must occur frequently, so that any change in their physical state is observed, anticipating a possible pathology that may occur.

Keywords: Railways, Permanent way, Pathological manifestations on the railway. 


\section{Introduçáo}

Nos dias atuais, a malha ferroviária brasileira sofre com a diferença entre as bitolas dos trilhos entre os estados, dificultando a ligação entre eles. Várias pesquisas afirmam que há duas explicações para tal situação. Uma delas seria que, para proteção, por volta de 1979, os estados optaram por utilizar diferentes tipos de bitolas, o que dificultaria uma possível invasão ou ataque de outro estado ou país [1]. Uma segunda vertente afirma que no início da construção da malha ferroviária, na Europa, utilizava-se de traçấo animal para puxar os vagóes e para a melhor disposição das bitolas era analisada a proporção traseira dos cavalos da Roma Antiga que possuía em torno de quatro pés e 8,5 polegadas. Essa forma de disposição das distâncias entre os trilhos também foi inicialmente utilizada aqui no Brasil [2].

Segundo [3], as ferrovias não vêm sendo utilizadas atualmente como foram no passado, entre as décadas de 30, 40 e 50, pois, com inovaçóes e investimentos exacerbados em outros modais, principalmente no rodoviário, este modal vem sofrendo com a falta de investimentos em conservação. A viabilização de um trecho é fundamental para o bom andamento de movimentaçáo de cargas e pessoas, tornando assim, o percurso mais confortável e ágil.

Dados de [4] demonstram que o Paraná é o quarto Estado com maior extensão da malha ferroviária, totalizando $2.287 \mathrm{~km}$, sendo que $2.039 \mathrm{~km}$ são operados pela empresa América Latina Logística do Brasil S/A- ALL. A estatal Ferrovia Paraná S/A opera os 248 km restantes, que cruzam onze municípios do Paraná, iniciando em Guarapuava estendendo-se até Cascavel, passando pelos municípios de Candói, Goioxim, Cantagalo, Marquinho, Laranjeiras do Sul, Nova Laranjeiras, Guaraniaçu, Ibema e Campo Bonito, entre outros.

Cascavel-PR possui uma área de $2.091 \mathrm{~km}^{2}$ e localiza-se na regiáo Oeste do Estado do Paraná. É considerada uma cidade-polo de uma região com um dos maiores entroncamentos rodoviários do Brasil, com uma localização estratégica privilegiada no MERCOSUL, tendo uma vocação natural para a industrialização. "Nossa vocação natural é para a agroindústria, uma vez que estamos numa grande região produtora de grãos" [5].

Por ser uma cidade-polo da agroindústria, a quantidade de recursos disponíveis é muito grande. Com isso surge a necessidade de haver a manutençáo da via permanente de uma ferrovia. A mesma é de tal importância para que de fato não ocorram desperdícios, sem que se perceba. Nesse passo entra a análise apurada nas vias permanentes, para se prever possíveis falhas e assim, sempre estar atento para um melhor aproveitamento dos recursos [6].

O presente trabalho teve como base a demonstração da importância do estado da via ferroviária para um bom escoamento de veículos com cargas, pois, é necessário entender quais são as maiores dificuldades de um trecho para se ter o embasamento de como fazer a manutenção correta do mesmo, visto que para cada patologia há um tipo de manutenção específica. Desta forma, buscou-se com o presente trabalho realizar um levantamento das manifestaçôes patológicas do trecho da via férrea 
do Posto Cascavel até o Posto Campo Bonito - PR, da FERROESTE e sugerir procedimentos de manutenção das mesmas.

\section{Metodologia}

O presente trabalho foi baseado no Manual de Inspeçôes da GECOF (Gerência de Controle e Fiscalização de Serviços e Infraestrutura de Transporte Ferroviário) que estabelece critérios e procedimentos para as inspeçôes relativas à fiscalização do transporte ferroviário de cargas realizado sob a responsabilidade das concessionárias desse serviço público, tanto em aspectos relacionados à exploração da infraestrutura como em questôes relativas à própria prestação desses serviços.

No caso deste trabalho, a pesquisa buscou levantar visualmente as manifestaçôes patológicas em um trecho ferroviário (qualitativa), assim como relacioná-las às causas de seu surgimento e métodos de correção, com base em normas e livros (descritiva).

Com relação aos objetivos, a pesquisa procurou identificar as patologias que surgiram no trecho analisado, bem como os métodos corretivos viáveis. Quanto aos procedimentos, a pesquisa é caracterizada como um estudo de caso, que relaciona vários aspectos de um mesmo fenômeno, por meio de inspeção visual e fotográfica, para que fossem identificadas e tabeladas as patologias no decorrer dos quilômetros.

O estudo ocorreu no trecho do Posto Cascavel até o Posto Campo Bonito da Via Permanente da FERROESTE. O trecho compreendeu 25 quilômetros, sendo esses bastante sinuosos. A vistoria foi realizada quilômetro á quilômetro, e foram identificadas as patologias encontradas no trecho analisado.

Os registros fotográficos serviram como mapeamentos das manifestaçôes patológicas identificadas, juntamente com a coleta de dados. Posteriormente, são apresentados gráficos que auxiliam na análise geral do estudo.

\section{Resultados}

Foram analisados $25 \mathrm{~km}$ de Via Permanente ligando o Posto Cascavel até o Posto Campo Bonito da FERROESTE em Cascavel - PR, desses a incidência ocorreu em apenas $12 \mathrm{~km}$ de via permanente, das mais distintas origens.

Na Tabela 1a-b a seguir, estão apontados os dados coletados durante a pesquisa. Constam neste quadro os quilômetros analisados e os problemas patológicos apresentados em cada quilômetro da

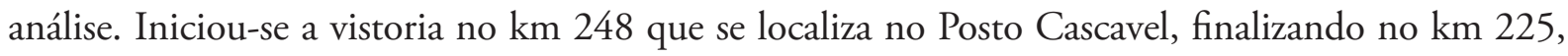
localizado no Posto Campo Bonito, sendo as patologias detalhadas a cada trecho de $1 \mathrm{~km}$. 
Tabela 1a - Patologias encontradas por quilômetros.

\begin{tabular}{|c|c|}
\hline km & Patologias \\
\hline 248 & Posto Cascavel \\
\hline \multirow{2}{*}{247} & Crescimento de vegetação; Desgaste lateral do trilho; Escamação do boleto; \\
\hline & Fratura em dormente de concreto; Martelamento de junta; \\
\hline \multirow{2}{*}{245} & Crescimento de vegetação; Desgaste lateral do trilho; Desgaste ondulatório; \\
\hline & Despedaçamento do canto da bitola; \\
\hline \multirow{2}{*}{243} & Crescimento de vegetação; Desgaste lateral do trilho; \\
\hline & Fissuração no canto da bitola; Trinca de patinação de roda \\
\hline \multirow{2}{*}{240} & Desgaste ondulatório; Despedaçamento do canto da bitola; \\
\hline & Escamação do boleto; Fissuração no canto da bitola; Martelamento de junta; \\
\hline \multirow{2}{*}{238} & Despedaçamento do canto da bitola; Desgaste ondulatório; \\
\hline & Esmagamento de boleto; \\
\hline 237 & Flambagem de via; Crescimento de vegetação; \\
\hline \multirow{2}{*}{235} & Crescimento de vegetação; Desgaste lateral do trilho; Esmagamento de boleto; \\
\hline & Fissuraçáo no canto da bitola; Lama em Excesso; Trinca de patinaçáo de roda; \\
\hline \multirow{3}{*}{233} & Desgaste ondulatório; Despedaçamento do canto da bitola; \\
\hline & Fissuração no canto da bitola; Trinca de patinação de roda; \\
\hline & Crescimento de vegetação; Desgaste ondulatório; \\
\hline \multirow[t]{2}{*}{232} & Despedaçamento do canto da bitola; Fissuração no canto da bitola; \\
\hline & Martelamento de junta; Trinca de patinaçáo de roda; \\
\hline \multirow{3}{*}{229} & Crescimento de vegetação; Desgaste lateral do trilho; Desgaste ondulatório; \\
\hline & Despedaçamento do canto da bitola; Martelamento de junta; \\
\hline & Crescimento de vegetação; Desgaste lateral do trilho; Desgaste ondulatório; \\
\hline \multirow[t]{2}{*}{228} & Despedaçamento do canto da bitola; Esmagamento de boleto; \\
\hline & Martelamento de junta; Trinca de patinação de roda; \\
\hline
\end{tabular}

Tabela $\mathbf{1 b}$ - Patologias encontradas por quilômetros.

\begin{tabular}{|c|c|}
\hline $\mathbf{k m}$ & $\begin{array}{r}\text { Patologias } \\
\end{array}$ \\
\hline \multirow{4}{*}{226} & Crescimento de vegetação; Desgaste lateral do trilho; \\
\hline & Despedaçamento do canto da bitola; Escamação do boleto; \\
\hline & Esmagamento de boleto; Estilhaçamento do canto da bitola; \\
\hline & Martelamento de junta; Trinca de patinação de roda; \\
\hline 225 & Posto Campo Bonito \\
\hline
\end{tabular}

$\mathrm{Na}$ Tabela 2 estão listadas as patologias encontradas e a sua quantificação, como também o percentual das mesmas em relaçáo ao total, sendo que as patologias não são comuns a todos os quilômetros analisados. É possível verificar que as patologias mais incidentes foram o crescimento de vegetação com $15,25 \%$ de incidência, seguido do despedaçamento de canto de bitola (13,56\%), desgaste lateral do trilho e desgaste ondulatório ambos com $(11,86 \%)$ e martelamento de junta e trinca de patinação de roda, ambos com (10,17\%). Portanto, estas patologias somadas, correspondem a aproximadamente $73 \%$ de todas as patologias encontradas. 
Tabela 2 - Ocorrências das patologias.

\begin{tabular}{lcc}
\hline \multicolumn{1}{c}{ Patologias } & Quantidade & Ocorrência ( \% ) \\
\hline Crescimento de vegetação & 9 & 15,25 \\
Despedaçamento do canto de bitola & 8 & 13,56 \\
Desgaste lateral do trilho & 7 & 11,86 \\
Desgaste ondulatório & 7 & 11,86 \\
Martelamento de junta & 6 & 10,17 \\
Trinca de patinação de roda & 6 & 10,17 \\
Fissuração no canto da bitola & 5 & 8,47 \\
Esmagamento de boleto & 4 & 6,78 \\
Escamaçáo do boleto & 3 & 5,08 \\
Estilhaçamento do canto da bitola & 1 & 1,69 \\
Flambagem de via & 1 & 1,69 \\
Fratura em dormente de concreto & 1 & 1,69 \\
Lama em Excesso & 1 & 1,69 \\
\hline \multicolumn{1}{c}{ Total } & $\mathbf{5 9}$ & $\mathbf{1 0 0}$ \\
\hline
\end{tabular}

$\mathrm{Na}$ Figura 1 a seguir, observa-se uma das patologias mais incidentes no trecho, denominada crescimento de vegetação, com 15,25\% de incidência na via. Em grande parte da via foi encontrada tal patologia, percebe-se que a vegetação transpôs os trilhos e alojou-se entre os dormentes e suas imediaçôes. Para se evitar tal patologia é indicada a manutenção da via, com corte e retirada da vegetação rasteira.

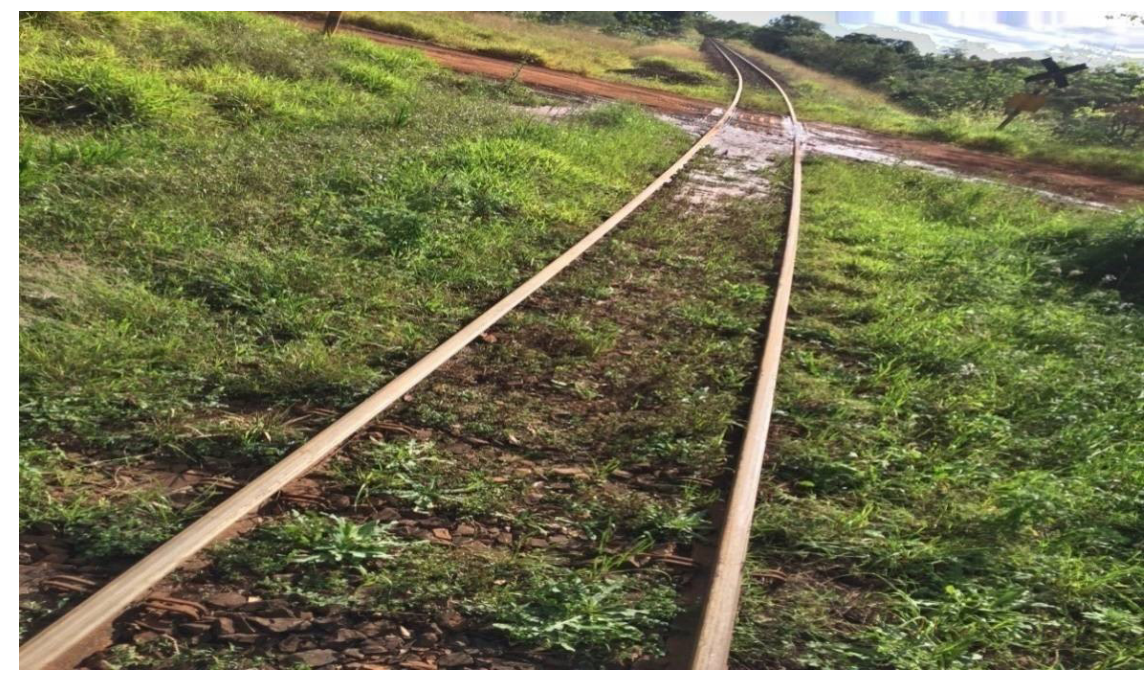

Figura 1 - Crescimento de Vegetação entre os trilhos e seus arredores.

Verificou-se que o despedaçamento do canto de bitola teve um percentual de $13,56 \%$ de incidência, pois é um defeito de fadiga de contato entre o material rodante e a superfície da bitola (Figura 2). Ele não é uma anomalia grave inicialmente, porém, com o passar do tempo, o escoamento do metal pelo tráfego provoca um desnivelamento no boleto, podendo atingir proporçóes graves e se 
tornando um perigo muito grande de acidentes. A manutenção preventiva é a melhor saída para tal patologia, identificado inicialmente pode-se prever uma mudança de velocidade no trecho pelo trem. Como correção para essa patologia sugere-se a troca do trilho.

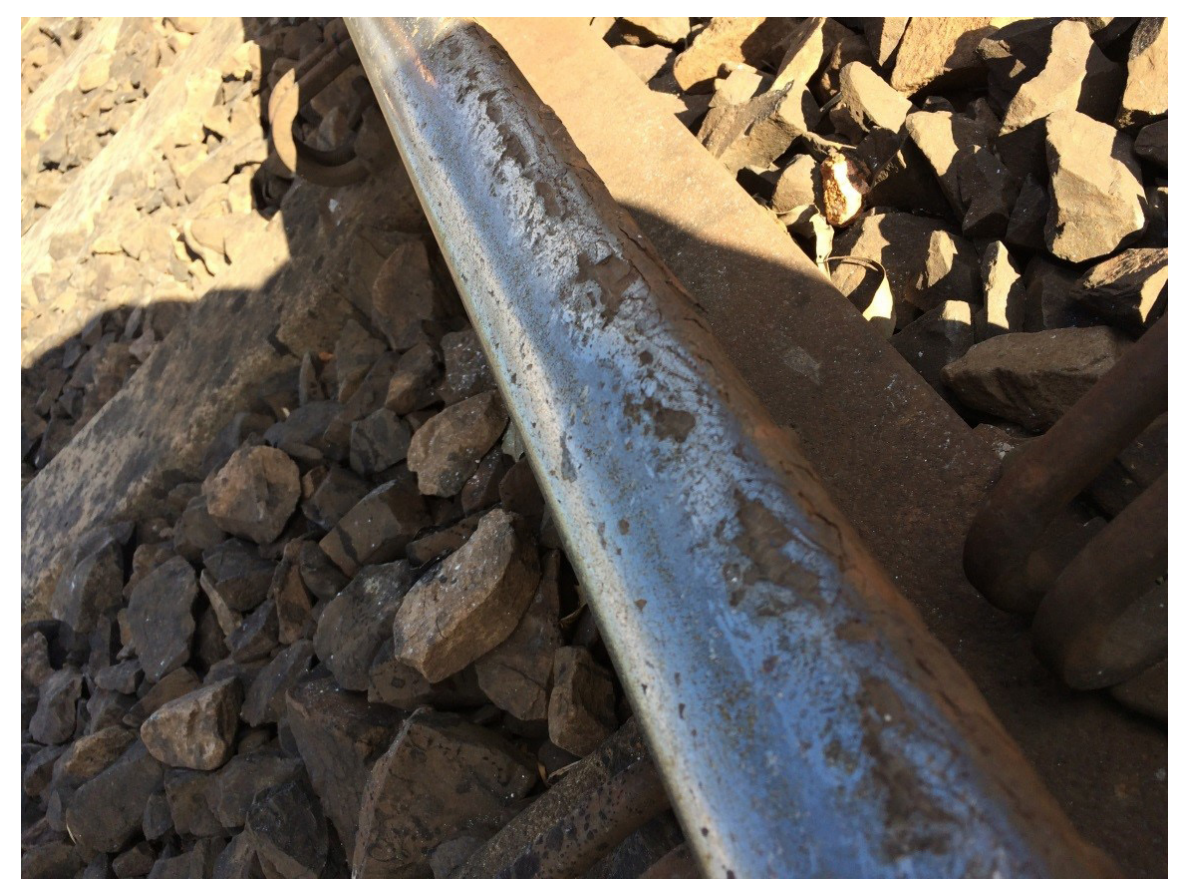

Figura 2 - Despedaçamento do canto de bitola na Via Permanente.

O desgaste lateral do trilho e o desgaste ondulatório se igualaram na porcentagem de incidência na via $(11,86 \%)$. São patologias entre roda/trilho, mas com algumas particularidades. No desgaste lateral, os frisos das rodas, durante a passagem pelas curvaturas do traçado, desgastam a lateral do trilho, que com o passar do tempo se torna enfraquecido, podendo vir a fraturar (Figura 3). A correção dessa patologia, em tal ponto de desgaste, se dá somente pela troca do trilho. Em regime leve de desgaste pode haver uma ótima lubrificação na interface roda/trilho, diminuindo o desgaste. Também é recomendável o reperfilamento dos trilhos em alguns casos. Nas manutençôes preventivas na via, deve-se atentar se a mesma já apresenta sinais de desgaste. Caso sim, como medida de prevenção, deve-se instaurar baixa velocidade na regiáo. 


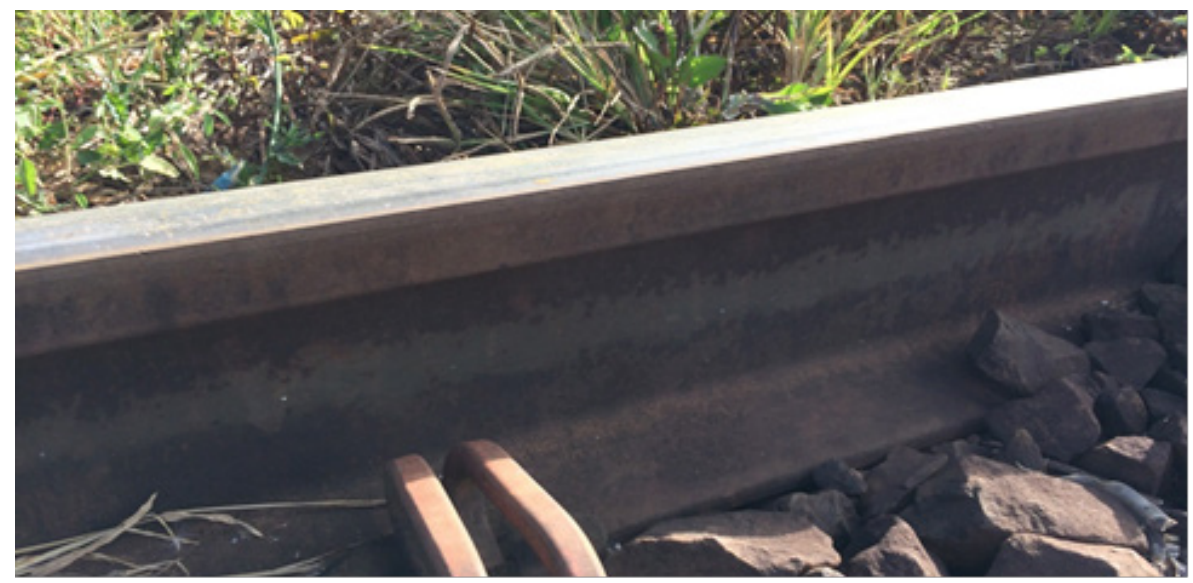

Figura 3 - Desgaste lateral do trilho por material rodante.

O desgaste ondulatório pode ser ligado à presença de elevadas cargas a baixas velocidades, cargas leves a maiores velocidades, desbalanceamento de rodas e eixos ou vibração na linha.

A concavidade é instaurada pelo contado da roda que pode estar com concavidades ao entrar em contato com o trilho. Em relação ao desgaste ondulatório, em alguns casos, a lubrificação ou o reperfilamento transversal do trilho, podem ser as melhores atitudes, porém, em outros, existe apenas a substituição do mesmo como solução (Figura 4).

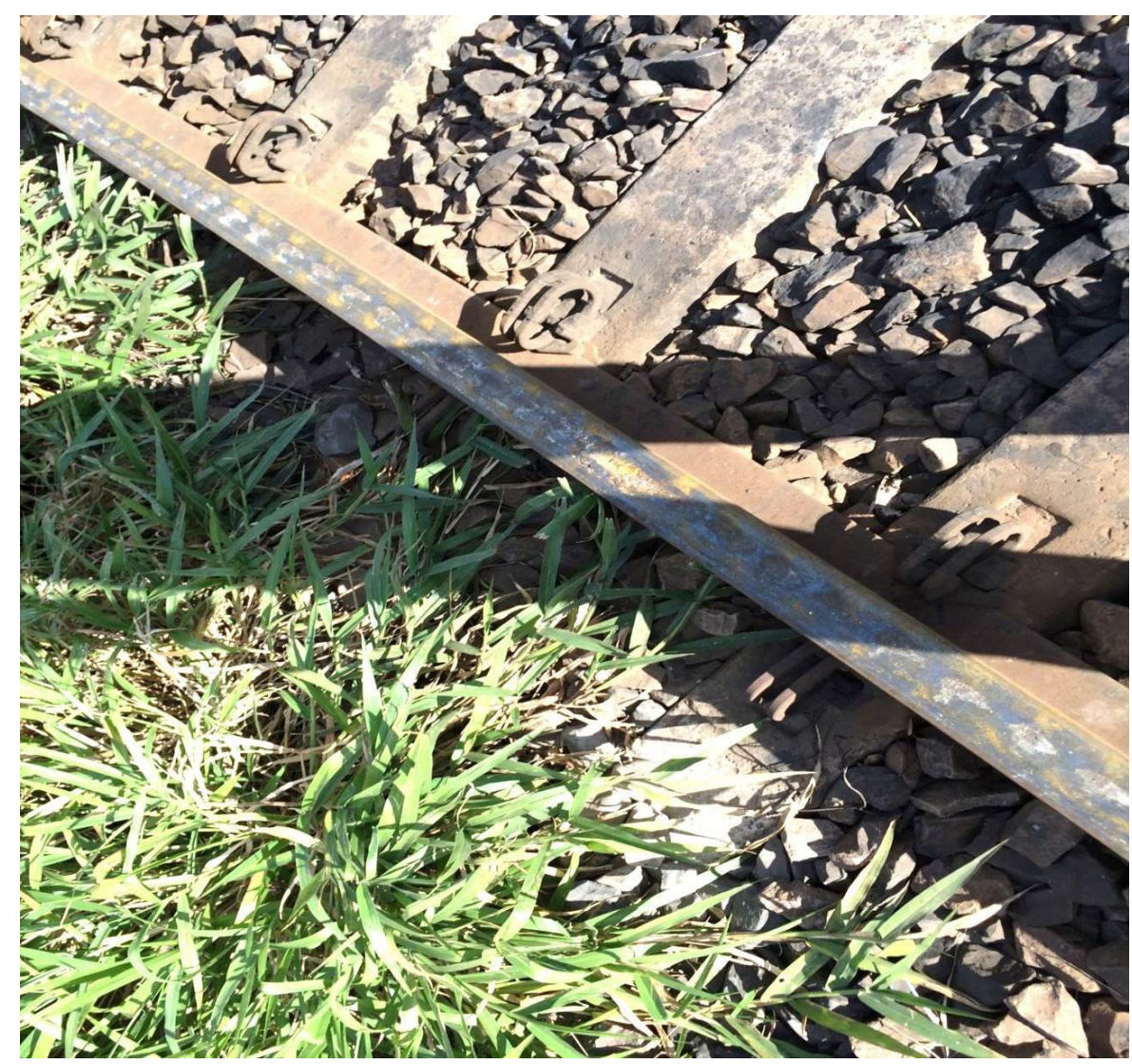

Figura 4 - Desgaste ondulatório do trilho. 
Nas Figuras 5 e 6 pode-se visualizar a patologia denominada martelamento de junta com incidência de 10,17\%, que tem origem nas junçôes mecânicas e nas talas parafusadas nas faces das almas, normalmente gerada pelo choque, por meio do material rodante em sua passagem pela folga deixada para a dilatação do trilho. É um dos defeitos mais graves na via permanente, pois pode ser causador de muitos acidentes. Com o passar do tempo, também pode levar a outras patologias, como despedaçamento do canto de boleto.

A correção dessa patologia se dá por uma nova fixação da tala de junção quando em um estado inicial e manutenção da mesma para não deixar que haja deslocamentos. Em um estado avançado o que se pode fazer é o corte da parte danificada e realização de uma nova junção.

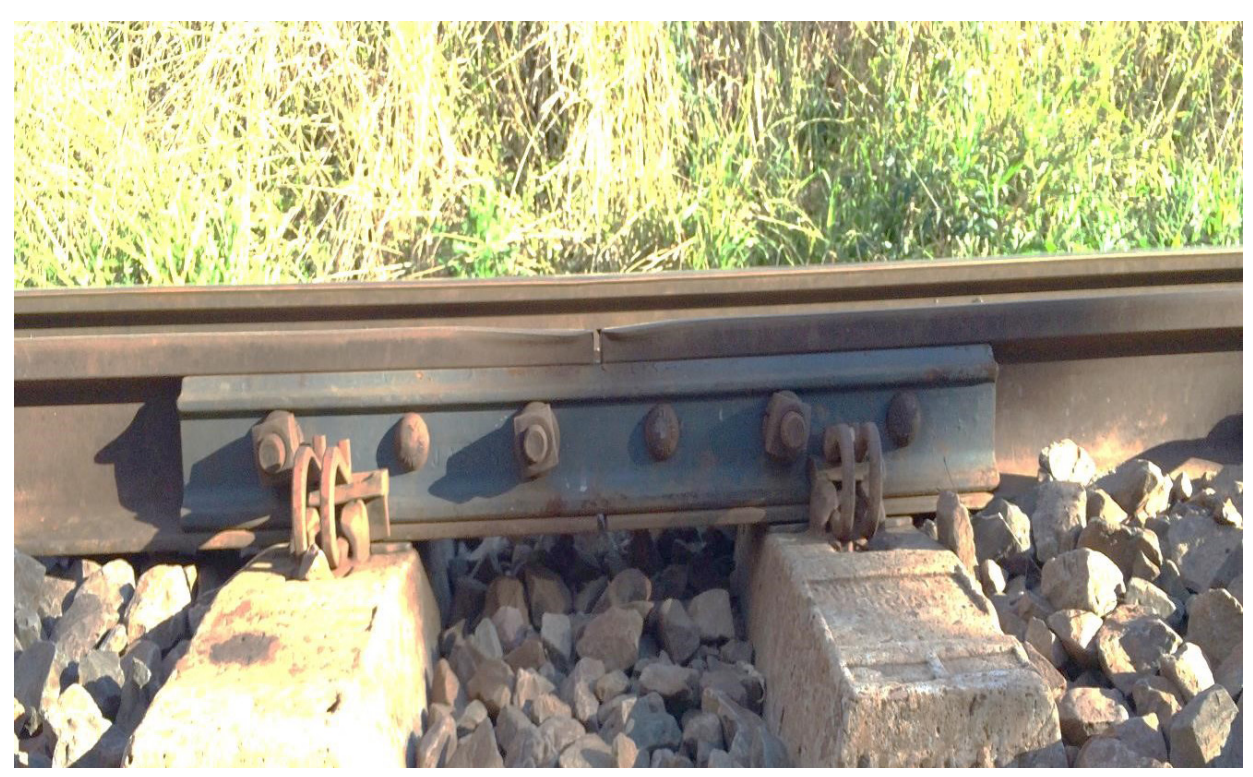

Figura 5 - Martelamento de junta de dilatação (Vista).

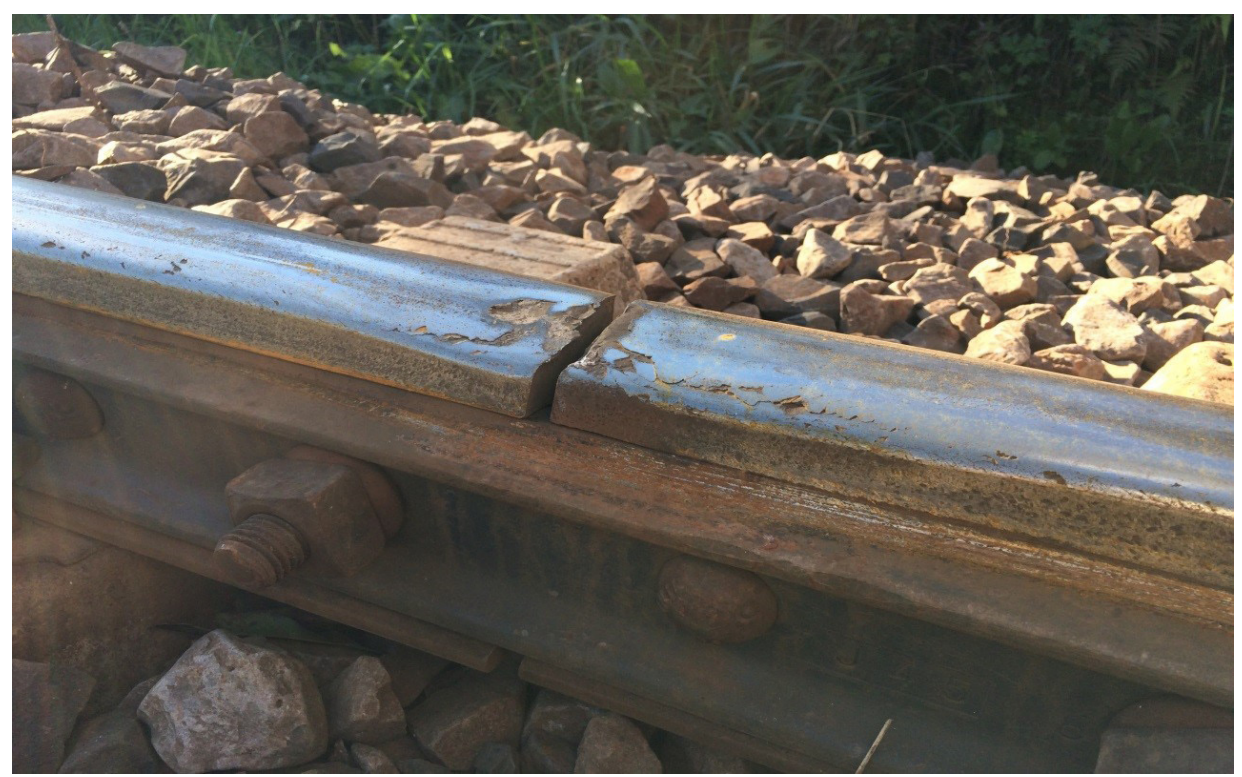

Figura 6 - Martelamento de junta de dilatação (Planta). 
Trinca de patinação de roda (Figura 7) é uma avaria na superfície de rolamento ocasionada pelo material rodante, por eventual atrito entre roda/trilho, por rodagem no mesmo lugar, sem movimentação do trem. O atrito e o calor gerado nesse deslizamento ocasionam a escavação da superfície do trilho, levando ao surgimento de outras patologias como as trincas transversais ao boleto. Geralmente, se manifesta em pátios, fortes rampas (subidas), trilho úmido ou engraxado. Deve-se focar em medidas preventivas em paradas e arrancadas, para não forçar o trilho com uma marcha muito pesada. Na manutenção da via não permitir resíduos de materiais graxos sobre os trilhos.

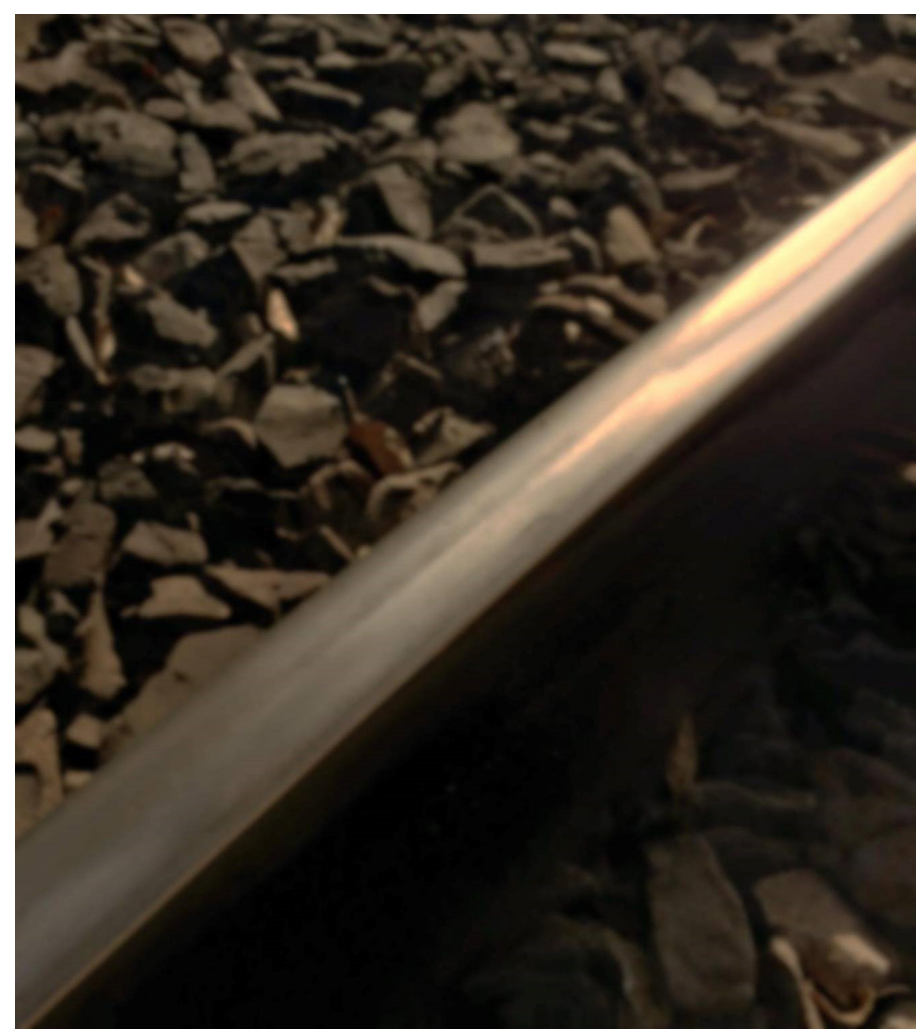

Figura 7 - Trinca por patinação de roda.

Do trecho analisado, $12 \mathrm{~km}$ apresentaram patologias. Deste total, foram constatadas 59 patologias, sendo possível notar que o km 226 tem a maior incidência de patologias e o km 237 a menor como demonstrado na Tabela 3 a seguir. 
Tabela 3 - Ocorrência de patologias encontradas nos trechos.

\begin{tabular}{ccc}
\hline $\mathbf{k m}$ & Quantidade & Ocorrência ( \% ) \\
\hline $\mathbf{2 2 6}$ & 8 & 13,56 \\
$\mathbf{2 2 8}$ & 7 & 11,86 \\
$\mathbf{2 3 2}$ & 6 & 10,17 \\
$\mathbf{2 3 5}$ & 6 & 10,17 \\
$\mathbf{2 2 9}$ & 5 & 8,47 \\
$\mathbf{2 4 0}$ & 5 & 8,47 \\
$\mathbf{2 4 7}$ & 5 & 8,47 \\
$\mathbf{2 3 3}$ & 4 & 6,78 \\
$\mathbf{2 4 5}$ & 4 & 6,78 \\
$\mathbf{2 4 3}$ & 4 & 6,78 \\
$\mathbf{2 3 8}$ & 4 & 5,08 \\
$\mathbf{2 3 7}$ & 3 & 3,39 \\
\hline Total & 2 & $\mathbf{1 0 0}$ \\
\hline
\end{tabular}

\section{Conclusóes}

Por meio deste estudo foi possível identificar, quantificar e avaliar as manifestaçóes patológicas presentes no trecho do Pátio Cascavel ao Pátio Campo Bonito - PR da Via Permanente da FERROESTE. Observou-se que as patologias que ocorreram com maior frequência foram o crescimento de vegetação, despedaçamento do canto de bitola, desgaste lateral do trilho, desgaste ondulatório, martelamento de juntas e trinca de patinaçáo de roda.

Das patologias, a mais grave é o despedaçamento do canto de bitola, pois se trata de uma anomalia, inicialmente não muito grave, porém, com o passar do tempo pode atingir proporçóes graves, causando acidentes. Notou-se também que pela falta de manutenção da via permanente, o crescimento de vegetação entre os trilhos e seus arredores foi à patologia mais incidente, pois atingiu vários pontos da via.

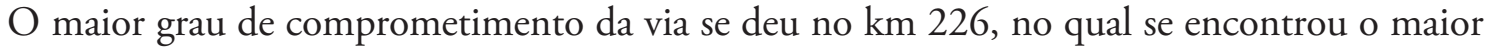
índice patologias do percurso, ressaltando que dos $25 \mathrm{~km}$ analisados, $12 \mathrm{~km}$ apresentaram patologias. Logo, com esse estudo se percebeu a importância da manutenção preventiva na via permanente. Além do controle do uso da via, medidas como fiscalização dos trilhos devem ocorrer com frequência, evitando qualquer alteração no seu estado físico, antecipando uma possível patologia, estabelecendo a lubrificação adequada entre as rodas das locomotivas e os trilhos. Isso pode proporcionar um bom desempenho da via, e fazer a montagem das juntas de dilatação adequadas e com o espaçamento e fixação corretos como formas de prevenção.

O assunto ferrovias deveria estar cada vez mais presente no cotidiano do brasileiro, pois com rodovias cada vez mais congestionadas, deve-se explorar com maior intensidade outros meios de transporte. Entretanto, com o al to descaso em que se encontra a malha ferroviária brasileira, há mui- 
to trabalho a ser feito, pois, um país desenvolvido investe em seus meios de transportes, pois eles são fundamentais para que haja a integração dos setores econômico, social e cultural das cidades.

\section{Agradecimentos}

Estrada de Ferro Paraná Oeste S. A. (FERROESTE).

\section{Referências}

[1] CURY, M. V. Q. Estudo de Bitolas, 2011. Disponível em: <http://marcusquintella.com.br/sig/lib/uploaded/ producao/ESTUDO_DE_BITOLAS.pdf>. Acesso em: 26 out. 2017.

[2] LUIZ, S. Conexão engenharia do futuro, 2011. Disponível em: <http://eng-civilsergiopeixotto.blogspot.com. br/2011_11_01_archive.html> Acesso em: 26 out. 2017.

[3] LISBOA, S. Editora Abril. Super Interessante. Por que o transporte ferroviário é táo precário no Brasil? 2013. Disponível em: <http://super.abril.com.br/cotidiano/transporte-ferroviario-tao-precario-brasil-740045.shtml>. Acesso em: 26 out. 2017.

[4] FERROPAR, Ministério dos Transportes. Estrada de Ferro Paraná Oeste S.A - FERROESTE. Histórico da ferrovia, 2007. Disponível em: <http://www.transportes.gov.br/bit/03-ferro/3-princ-ferro/1-princ-emp-ferro/ferropar/ links/inf-fepar.htm>. Acesso em: 26 out. 2017.

[5] MELLO, A. Jornal Hoje. Industrializaçáo, 2008. Disponível em: <http://www.jhoje.com.br/17082008/politica. php>. Acesso em: 28 jun. 2014.

[6] MAGAlHÃES, P. C. Via Permanente. Notas de aulas na especialização em Transporte Ferroviário de Carga do Instituto Militar de Engenharia. Belo Horizonte, 2007. Disponível em: <http://transportes.ime.eb.br>. Acesso em: 26 out. 2017. 